\title{
AB Block Copoly(3-alkylthiophenes): Synthesis and Chiroptical Behavior
}

\author{
Michiel Verswyvel, Frederic Monnaie, and Guy Koeckelberghs* \\ Laboratory of Polymer Synthesis, Katholieke Universiteit Leuven, Celestijnenlaan 200F, 3001 Heverlee (Leuven), Belgium
}

Supporting Information

ABSTRACT: In a first part of this article, the synthesis of $A B$ type block copoly(3-alkylthiophene)s initiated by $\mathrm{Ni}(\mathrm{dppp}) \mathrm{Cl}_{2}$, the most commonly used initiator for these polymers, is investigated. For this study the respective ${ }^{1} \mathrm{H}$ NMR resonances of all possible end-groups are identified. This result confirms the hypothesis that the Ni(dppp) species can walk back to the beginning of the polymer chain and that propagation can occur at both chain ends. The next part of the article studies the chiroptical behavior of AB-type block copoly(3-alkylthiophene)s with one chiral block and compares the results with
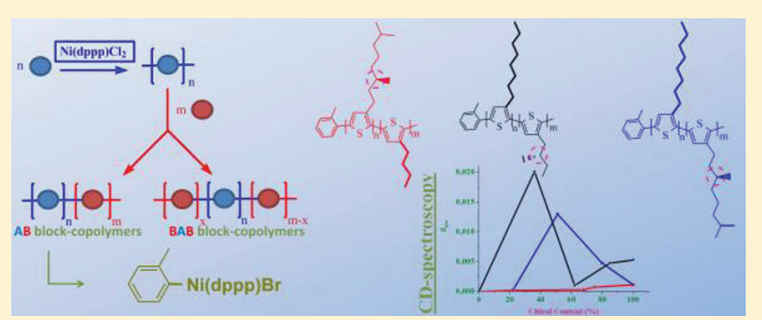
those of the corresponding random copolymers. In order to obtain exclusively AB-type block copolymers, the polymers were prepared from a modified Ni initiator. They all have the same degree of polymerization but vary in the length of the respective blocks. The chiroptical behavior was studied by changing the ratio solvent/nonsolvent, meanwhile monitoring the UV-vis and circular dichroism (CD) spectra. Three series were investigated: one in which both blocks aggregate simultaneously, one in which the achiral block stacks before the chiral block, and one in which the chiral block stacks first followed by the achiral block. It was found that when the blocks stack independently, the (chiral/achiral) stacking of the latter is significantly influenced by the former. If both blocks of the polymer chains aggregate simultaneously, Cotton effects which are significantly larger than those of the chiral homopolymer are found.

\section{INTRODUCTION}

The field of conjugated polymers emerges at a continuously increasing speed. For a long time researchers have almost exclusively been driven by applications, such as transistors, photovoltaics, light-emitting diodes, etc. ${ }^{1}$ A major synthetic breakthrough was realized when the groups of $\mathrm{McCullough}^{2}$ and Yokozawa ${ }^{3}$ demonstrated that the $\mathrm{Ni}(\mathrm{dppp}) \mathrm{Cl}_{2}$-initiated $(\mathrm{dppp}=1,3$-bis (diphenylphosphino)propane $)$ polymerization of poly(3-alkylthiophene)s (P3ATs) using a Kumada coupling reaction proceeds via a controlled chain-growth mechanism. This allows the polymerization of P3ATs, and later also other monomers, ${ }^{4}$ often of predictable molar mass and a controlled molecular structure. Moreover, with this mechanism, block copolymers can be prepared by successive monomer additions. ${ }^{5}$ Also, block copolymers composed of two different alkylthiophenes were prepared, and it was found that if the alkyl substituents differ more than two carbon atoms in length, phase separation occurs. ${ }^{5 \mathrm{~b}, 6}$

The controlled nature of the $\mathrm{Ni}(\mathrm{dppp})$-mediated polymerization can be obtained because after reductive elimination (RE), the $\mathrm{Ni}$ (dppp) species remains complexed with the $\pi$-conjugated backbone. Very recently, Kiriy and co-workers postulated the possible "walking" of the catalyst moiety from one end to the other during the polymerization. ${ }^{7}$ When the polymerization is initiated with $\mathrm{Ni}(\mathrm{dppp}) \mathrm{Cl}_{2}$ and, consequently, polymers with two active carbon-bromine bonds are formed, this can result in polymer chains growing from both sides of the initially formed tail-to-tail dyad. This has an important consequence on the block copolymer formation. If two electronically equal polymer blocks are polymerized using $\mathrm{Ni}(\mathrm{dppp}) \mathrm{Cl}_{2}$ as the initiator, for instance P3ATs with different alkyl substituents, the catalyst might travel along the polymer chain and a batch of $\mathrm{AB}$ block copolymers (originating from unidirectional growth) will be obtained, together with $\mathrm{BAB}$ block copolymers which are formed when $\mathrm{Ni}(\mathrm{dppp})$ walks back to the other end of the polymer after the $\mathrm{B}$ monomer has started to polymerize (bidirectional growth).

Apart from progress on the mechanistic aspects of their polymerization, the chiroptical properties of (conjugated) polymers has been a topic of interest for many decades. Green et al. discovered the sergeants-and-soldiers and majority-rules behavior in polyisocyanates. ${ }^{8}$ This implies that the fraction of one-handed helices in random helical copolymers is higher than the fraction of chiral monomer or the enantiomeric excess (sergeants-and-soldiers and majority-rules, respectively) present in the chain. This results in a chiral response, which increases nonlinear with the fraction of chiral monomer or the enantiomeric excess. Meijer and co-workers have revealed that the majorityrules principle is present in random copoly(3-alkylthiophene)s and that sergeants-and-soldiers and majority-rules behavior can be found in stacks of chiral and achiral P3ATs which aggregate at

Received: September 22, 2011

Revised: $\quad$ November 7, 2011 

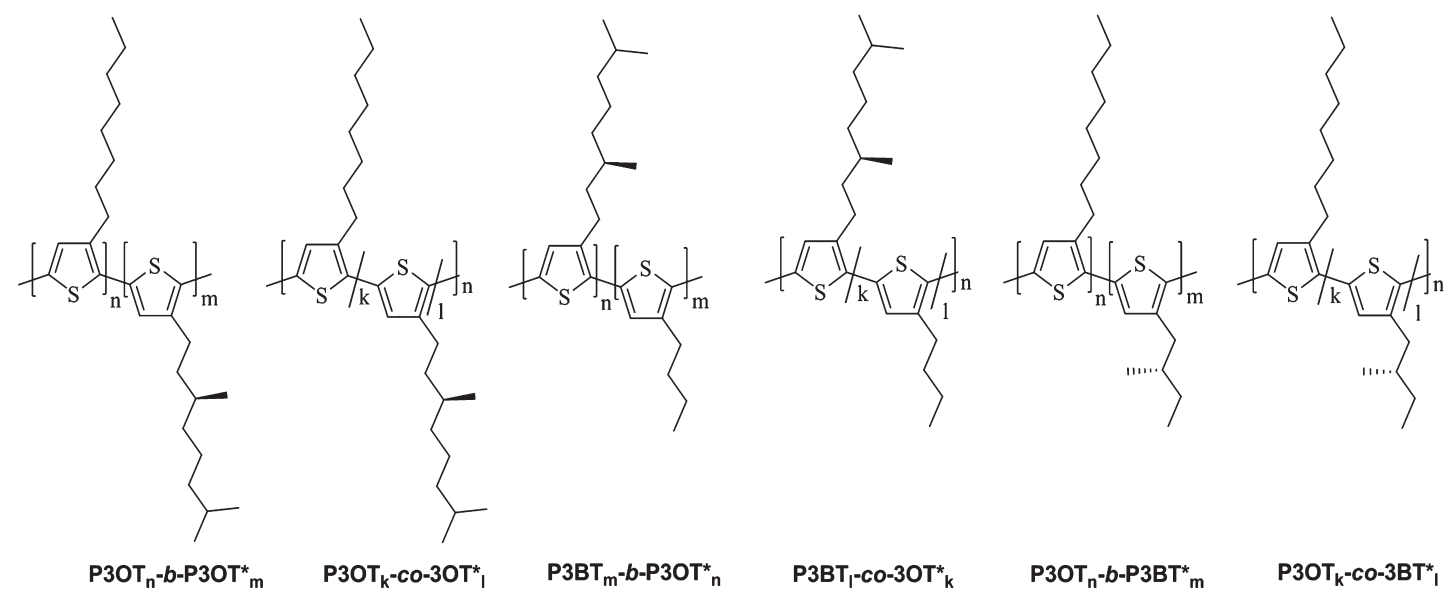

Figure 1. Structure of the block and random copolymers examined in this paper. For each polymer different values of $m, n, k$, and $l$ are synthesized.

the same nonsolvent content. ${ }^{51}$ We have prepared $\mathrm{AB}$ block copolymers composed of a P3AT and P3AOT block, of which one or both of them are chiral..$^{\mathrm{g}-\mathrm{h}} \mathrm{We}$ found that the block that aggregates first imposes restrictions to the aggregation of the second block, resulting in chiroptical properties which are unusual for that particular polymer and different from the blend.

In this article, the investigation of the chiroptical properties of block copoly(3-alkylthiophene)s composed of an achiral and a chiral block is described. While the total length of the block copolymers is fixed, the fraction of chiral monomers is varied by changing the length of this block. P3ATs were chosen for this study, since their polymerization proceeds via a controlled chain-growth mechanism, allowing to adjust the degree of polymerization of the blocks at wish and to prepare block copolymers by successive monomer addition in a one-pot synthesis. The length of the achiral side chains (butyl vs octyl) is chosen in such way that the block that aggregates first (the chiral or achiral) can be tuned. The chiroptical behavior is compared with random copolymers with the same monomer composition. Since the exclusive formation of AB-type block copolymers, which is required for this research, depends on the fact whether the polymer grows only unidirectionaly or not, in the first part of this article we describe the investigation whether unidirectional growth takes place in case of P3ATs. In the second part of the article, we describe the synthesis of the actual copolymers and their chiroptical properties are evaluated (Figure 1).

\section{RESULTS AND DISCUSSION}

Unidirectional vs Bidirectional Growth. As already mentioned, $\mathrm{Ni}(\mathrm{dppp})$ remains complexed to the propagating polymer chains in the polymerization of P3AT, and evidence is present that growth occurs on both sides of the polymer chains. ${ }^{7}$ For each propagation step, growth at the same end of the polymer is in any case more likely, since (i) after RE Ni(dppp) is located more close to the polymer's growing end and (ii) the $\mathrm{C}-\mathrm{Br}$ bond polarizes the last thiophene unit, directing the $\mathrm{Ni}$ (dppp) toward this end. Taken this into account, Kiriy showed that the probability that a polymer chain has grown only on one side is

$$
P(N)=N^{\delta-1}
$$

in which $N$ is the number of monomer units (degree of polymerization (DP)) and $\delta$ a "stickiness" parameter. Only if $\delta$ equals (or is very close to) 1, the polymer grows (almost) exclusively on one side. Quantification of $\delta$ can predict to which extent bidirectional growth takes place and whether $\mathrm{AB}$ or $\mathrm{BAB}$ block copoly(3-alkylthiophene)s will be obtained.

The first step in the polymerization of P3AT with $\mathrm{Ni}$ (dppp) $\mathrm{Cl}_{2}$ as a catalyst is a double transmetalation step of two monomer units on the $\mathrm{Ni}^{+I I}$ moiety, resulting in a tail-to-tail dyad (TT-dyad) (see Scheme 1). As long as the polymer chain grows in only one direction, the TT-dyad remains on one end of the polymer. Once the catalyst moves to the other end and promotes a propagation step there, the TT-dyad ends up on the inside of the polymer. The latter is accompanied by the disappearance of a carbon-bromine bond on the TT-dyad. Consequently, five different $\alpha$-methylene protons, and corresponding triplet signals in ${ }^{1} \mathrm{H}$ NMR spectroscopy, are expected. They are denoted as $\mathrm{Br}$-tail-to-tail (Br-TT), $\mathrm{Br}$-head-to-tail (Br-HT), H-head-totail (H-HT), tail-to-tail-head-to-tail (TT-HT), and head-totail-head-to-tail (HT-HT) (see Scheme 1). Using these signals, we can define the fraction of polymer chains grown only in one direction versus these grown on both directions. The more polymer chains have grown in both directions, the more TTdyads will be moved to the inner polymer chain; i.e., the bromine on the TT-dyad disappears, and as a consequence the triplet signal Br-TT weakens in favor of Br-HT. Indeed, the active side of the polymer chain will bear a hydrogen upon termination, and the other side retains a bromine.

For this reason, an accurate assignment of the signals is critical to define the walking behavior of the catalyst during the polymerization and the "stickiness" $(\delta)$. During the past years, effort was made to assign the triplet signals of the $\alpha$-methylene protons of the ${ }^{1} \mathrm{H}$ NMR spectra. Indeed, these signals will differ significantly depending on their environment. The triplet signals Br-HT, H-HT, and HT-HT have been already assigned. ${ }^{2 a, 9}$ Nevertheless, for the determination of $\delta$, also $\mathrm{Br}$-TT needs to be identified. When examinating the ${ }^{1} \mathrm{H}$ NMR spectrum of a P3AT polymer polymerized with the described protocol, a deviation of the integration between $\mathrm{Br}-\mathrm{HT}$ and $\mathbf{H}-\mathbf{H T}$ is clearly visible. From the living nature of the polymerization, one expects that every polymer chain has one $\mathrm{Br}$-end and one $\mathrm{H}$-end. Nevertheless, a Br-end can also be a $\mathrm{Br}$ on a TT-dyad, which is not covered by the Br-HT signal. Interestingly, another triplet is 
Scheme 1. Schematic Representation of the Polymerization of P3AT with $\mathrm{Ni}(\mathrm{dppp}) \mathrm{Cl}_{2}$ as a Catalyst ${ }^{a}$

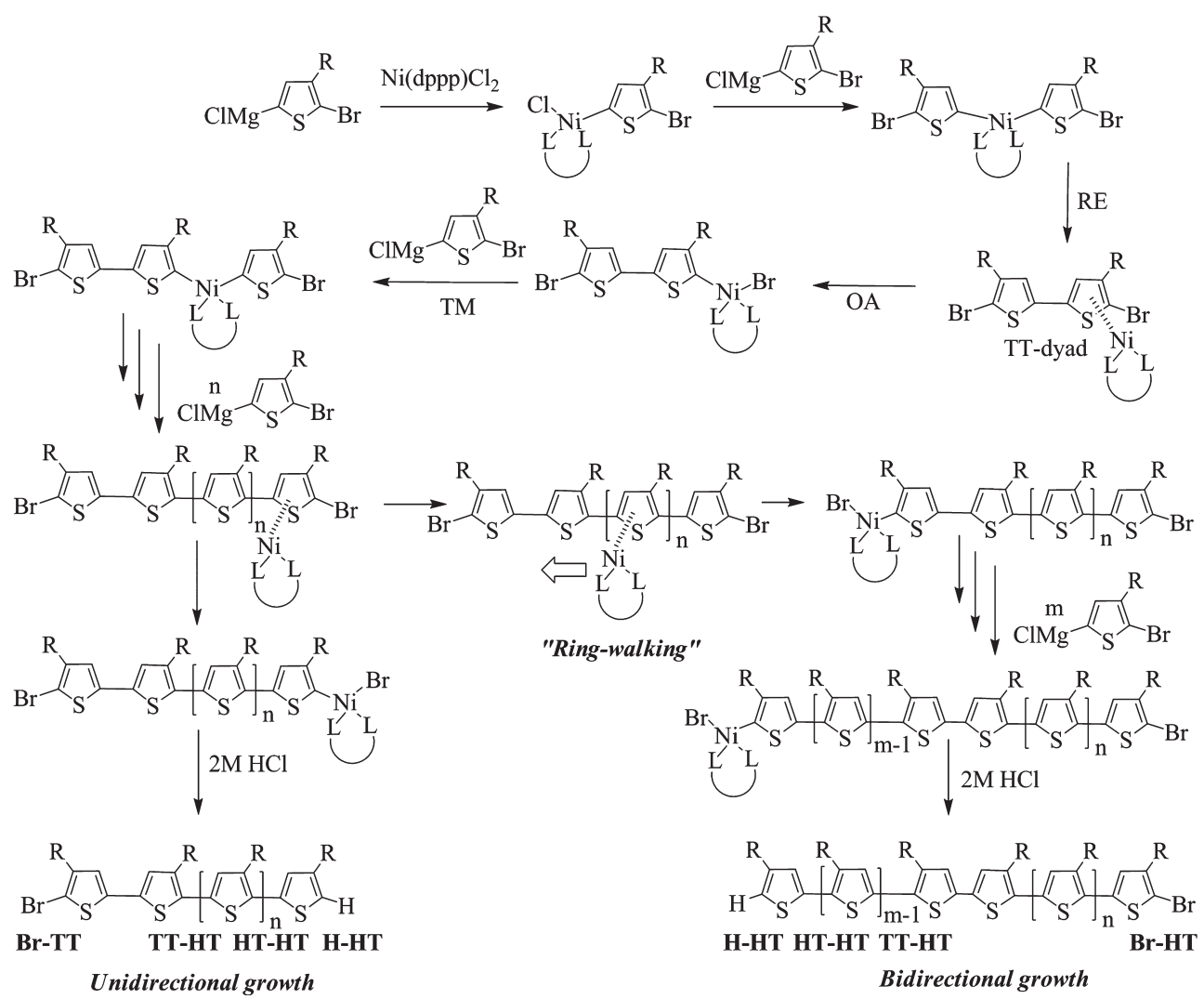

${ }^{a}$ Unidirectional and bidirectional growth and the consequences for the end-groups are shown. $\mathrm{RE}=$ reductive elimination; $\mathrm{OA}=$ oxidative addition; $\mathrm{TM}=$ transmetalation.

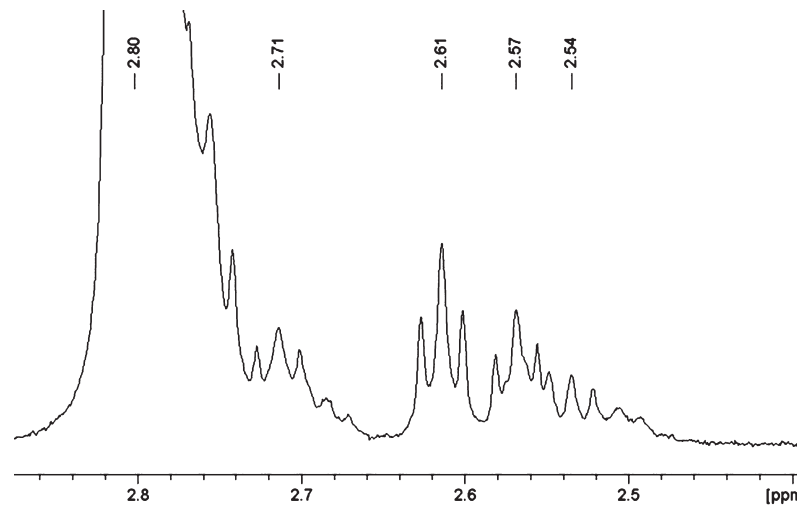

Figure 2. ${ }^{1} \mathrm{H}$ NMR spectrum $(600 \mathrm{MHz})$ of the $\alpha$-methylene protons in P3HT polymerized with $\mathrm{Ni}(\mathrm{dppp}) \mathrm{Cl}_{2}$ as a catalyst.

observed more downfield next to Br-HT. By adding its integration with this of $\mathbf{B r}-\mathbf{H T}$, an equal integration is obtained as for $\mathbf{H}$ HT. This lets us assume that the triplet at $2.54 \mathrm{ppm}$ is Br-TT.

To verify our hypothesis, a ter(3-alkyl)thiophene is prepared (Scheme 2) with a bromine on the TT-end. This allows us to assign Br-TT (2.54 ppm) correctly. Moreover, since also the TTHT dyad (2.71 ppm) is formed, the corresponding triplet signal could also be attributed. The synthesis of the terthiophene is performed in two steps. The bithiophene 3 was coupled with 4-hexyl-2-trimethyltinthiophene (2), which was prepared by lithiation of $\mathbf{1 b}$ on the 5-position with the in situ prepared
Scheme 2. Synthesis of the Ter(3-alkyl)thiophene 4

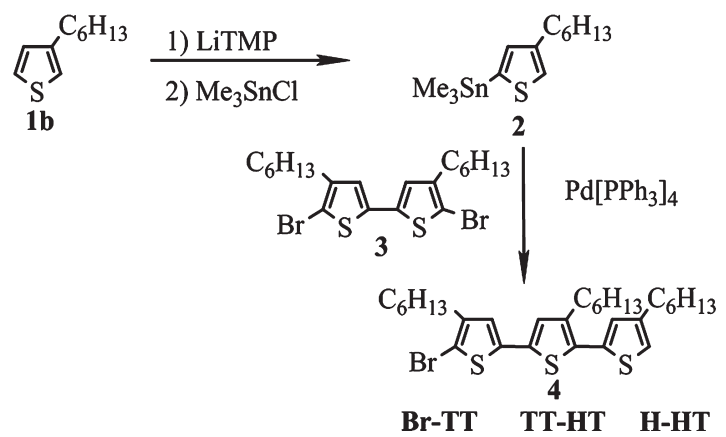

lithium-2,2,6,6-tetramethylpiperidine (LiTMP) and transmetalation with $\mathrm{Me}_{3} \mathrm{SnCl}$ to 2 .

The resonances of the three $\alpha$-methylenes of 4 were assigned (Figure 3). This confirms our hypothesis on the assignment of $\mathbf{B r}$ TT and TT-HT. By using the integration of Br-TT resulting from unidirectional growth and Br-HT originating from bidirectional growth, it is possible to calculate the fraction of the polymer chains with unidirectional growth $(\mathrm{P})$. Doing so for polymer chains with different degrees of polymerization $(N)$ allows us to determine $\delta$ accurately. Indeed, rearrangement of eq 1 results in

$$
\frac{\log (P)}{\log (N)}+1=\delta
$$


Two series of P3ATs with varying $N$ were prepared. Despite the use of poly(3-butylthiophene) (P3BT) in the second part of this article, we opted for poly(3-hexylthiophene) (P3HT) and poly(3-octylthiophene) (P3OT) because of solubility reasons. The precursor monomers $\mathbf{6 b}$ and $\mathbf{6 c}$ are synthesized as described in the literature. ${ }^{3 \mathrm{~b}}$ The 2-bromo-3-alkylthiophenes were iodinated with iodine and iodobenzene diacetate (Scheme 3 ). The precursor monomers $\mathbf{6 b}$ and $\mathbf{6 c}$ are converted in situ to the monomers $7 \mathbf{b}$ and $7 \mathbf{c}$ with $i-\mathrm{PrMgCl} \cdot \mathrm{LiCl}$ and polymerized with $\mathrm{Ni}(\mathrm{dppp}) \mathrm{Cl}_{2}$. After polymerization overnight, the reaction mixture is quenched with a $2 \mathrm{M} \mathrm{HCl}$ solution, precipitated in methanol, and dried.

The obtained $N$ and the ratio Br-TT/(Br-HT + Br-TT $)(P)$ for the synthesized P3HTs and P3OTs are summarized in Table 1. The degree of polymerization was calculated from the ${ }^{1} \mathrm{H}$ NMR spectra by setting the integration of the outer $\alpha$-methylene protons ( 2.61 to $2.54 \mathrm{ppm}$ ) at 2 ; consequently, the inner $\alpha$-methylene protons ( 2.80 to $2.71 \mathrm{ppm}$ ) integrate for $\mathrm{N}-2$. The observation that $\mathrm{Br}-\mathrm{HT}$ is always present and that the ratio of Br-TT/(Br-HT + Br-TT $)$ decreases with increasing degree of polymerization already points at bidirectional growth, i.e., $\delta<1$. Next, the $\delta$ for each $N$ was calculated. From these results, we can conclude that the value of the stickiness for P3HT and P3OT is 0.68 and 0.73 , respectively.

When we apply these values on the one-pot synthesis of block copolymers with two electronically equivalent blocks, the ratio of $\mathrm{AB}$ and $\mathrm{BAB}$ block copolymers formed can be predicted. We need to realize that during the polymerization of the first block (A) the catalyst moiety can "walk" from one end to the other without any influence on the final result of the block copolymer constitution. To define the probability for a block copolymer to be built in an $A B$ manner, only the contributions of $P$ during the polymerization of the second block needs to be taken into account. For this reason, the

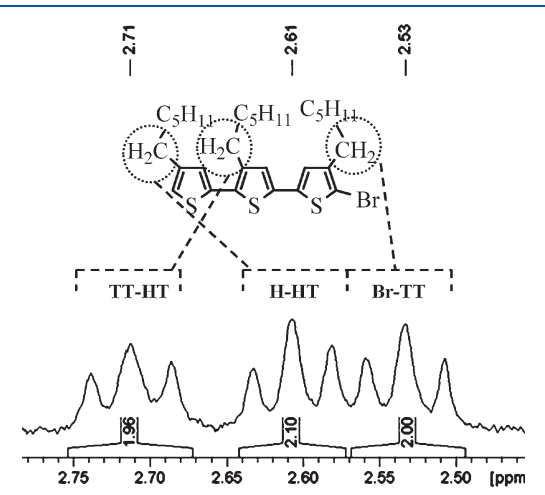

Figure 3. ${ }^{1} \mathrm{H}$ NMR spectrum of the terthiophene 4 (see full spectrum in Figure S6). formula which defines the probability to synthesize $A B$ block copolymers becomes

$$
P_{\mathrm{AB}}=\frac{P(N+M)}{P(N)}
$$

with $N$ and $M$ the degree of polymerization of the A and $\mathrm{B}$ block, respectively. The result is visualized in Figure S1. For instance, for a block copolymer with an A block of 30 monomers and a B block of 10 monomers, the probability for unidirectional growth is $\sim 91 \%$. In general, only for a long first block and a short second block the fraction of BAB block copolymers becomes negligible.

Consequently, since block copolymers with a totally different composition ( $\mathrm{AB}$ vs $\mathrm{BAB}$ ) are required for the chiroptical study (see further), this $\mathrm{Ni}(\mathrm{dppp}) \mathrm{Cl}_{2}$ cannot be used as initiator for these polymers. More in general, this implies that no batch of exclusively $\mathrm{AB}$ block copoly(3-alkylthiophene)s can be obtained (unless the first block is very large and the second very short), putting earlier reports on such polymerizations into perspective.

Chiroptical Behavior of Random and Block Copolymers. In this second part, the study of the chiroptical behavior of $A B$ block copolymers with one chiral and one achiral block is described. Since $\mathrm{Ni}(\mathrm{dppp}) \mathrm{Cl}_{2}$ fails in the exclusive formation of $\mathrm{AB}$ block copolymers, an adjusted initiator must be used. We opted for the functionalized bromo-(o-tolyl)-nickel(dppp) which is prepared in situ starting from the air-stable bromo- $(o-$ tolyl)-bis(triphenylphosphine)nickel $\mathbf{8}$ and dppp by stirring these two components for $30 \mathrm{~min}$ at room temperature in THF just before the polymerization. This functionalized initiator has only one reactive side, unlike the TT-dyad, and can therefore only grow in one direction. In order to allow comparison, the total length of all polymers remains the same (i.e., $n+m \approx 40$ ),

Table 1. Overview of the Number Average Molar Mass $\left(\bar{M}_{n}\right.$ As Determined by GPC, Polydispersity Index (PDI), the Obtained Degree of Polymerization (N) As Determined by ${ }^{1} \mathrm{H}$ NMR Spectroscopy, the Fraction of Unidirectional Growth $(P)$, and the Stickiness $(\delta)$ for the Synthesized Polymers

$\begin{array}{lccccc}\text { polymer } & \bar{M}_{\mathrm{n}}\left(\mathrm{kg} \mathrm{mol}^{-1}\right) & \text { PDI } & N & P(\%) & \delta \\ \text { P3HT }_{13} & 2.8 & 1.2 & 13 & 42 & 0.67 \\ \text { P3HT }_{18} & 3.5 & 1.3 & 18 & 39 & 0.68 \\ \text { P3HT }_{20} & 4.9 & 1.2 & 20 & 38 & 0.68 \\ \text { P3HT }_{24} & 6.3 & 1.2 & 24 & 35 & 0.67 \\ \text { P3HT }_{27} & 7.4 & 1.2 & 27 & 34 & 0.68 \\ \text { P3OT }_{12} & 3.8 & 1.3 & 12 & 48 & 0.71 \\ \text { P3OT }_{18} & 5.3 & 1.3 & 18 & 47 & 0.74 \\ \text { P3OT }_{22} & 7.5 & 1.3 & 22 & 43 & 0.73 \\ \text { P3OT }_{29} & 10.0 & 1.4 & 29 & 41 & 0.74\end{array}$

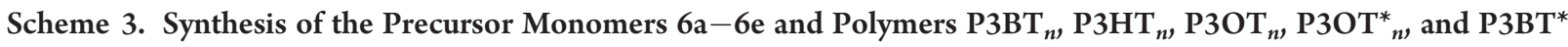

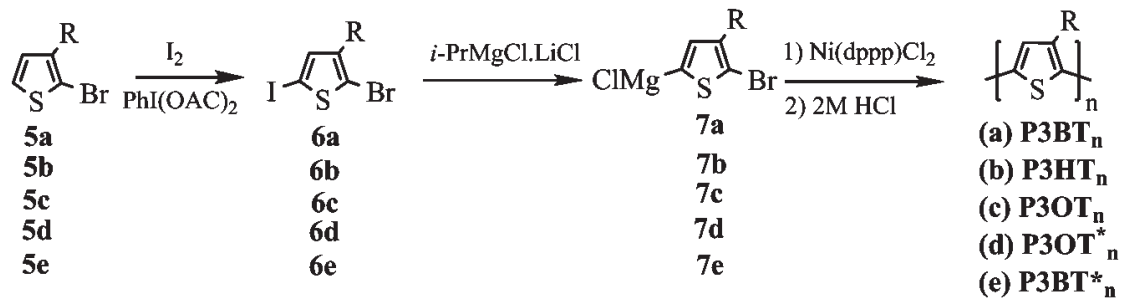

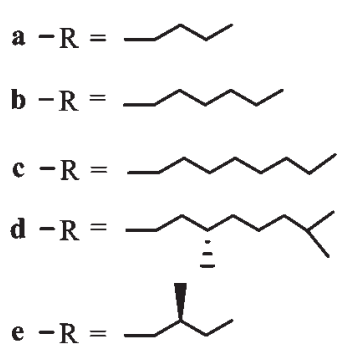




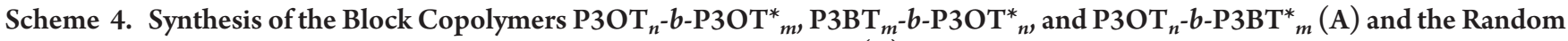

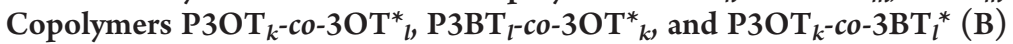
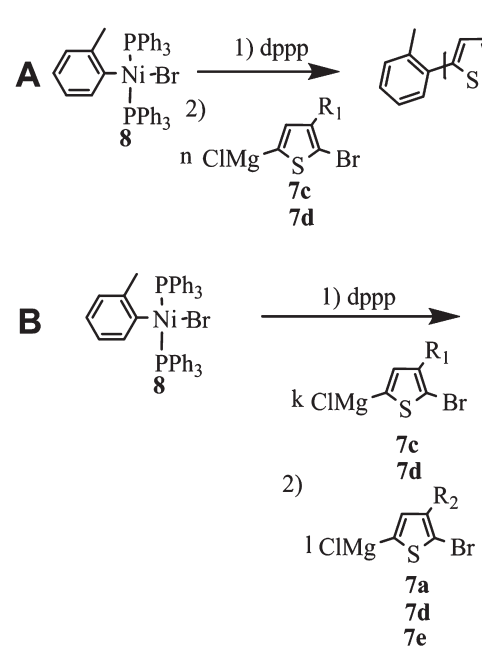
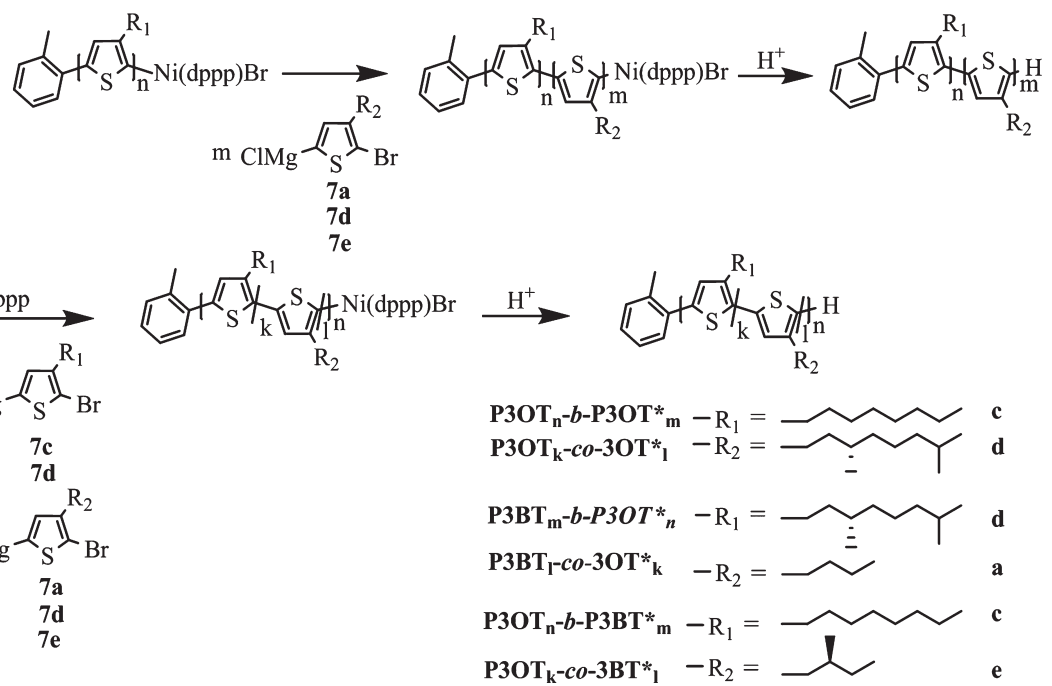

but the lengths of the respective blocks differ. Furthermore, the length of the achiral substituent was varied in order to allow separate or simultaneous aggregation of both blocks in the block copolymer when increasing amounts of nonsolvent (cf. poor solvent) is added. Moreover, it has been shown that a difference in length of at least two carbon atoms in the substituents on the two blocks is sufficient to induce microphase separation. ${ }^{6}$ As already mentioned, we synthesized and investigated the random copolymers analogues as well for comparison with the corresponding block copolymers. The precursor monomers $6 \mathrm{a}, 6 \mathrm{c}, 6 \mathrm{~d}$, and $6 \mathrm{e}$ are synthesized as depicted in Scheme 3. ${ }^{14,3 b, 5 h}$ All together, we synthesized poly(3-butylthiophene)-b-poly(3- $((S)$-3,7-dimethyloctyl)thiophene) (P3BT-b-P3OT*), poly((3-butylthiophene)co-(3-((S)-3,7-dimethyloctyl)thiophene)) (P3BT-co-3OT*), poly(3-octylthiophene)-b-poly(3-((S)-3,7-dimethyloctyl)thiophene) (P3OT-b-P3OT*), poly((3-octylthiophene)-co-(3- $((S)-3,7-d i-$ methyloctyl)thiophene)) (P3OT-co-3OT*), poly(3-octylthiophene)-b-poly(2-(S)-methylbutyl)thiophene) (P3OT-b-P3BT*), and poly ((3-octylthiophene)-co-(2-(S)-methylbutyl)thiophene)) (P3OT-co-3BT $\left.{ }^{*}\right)$, each time with different lengths of the chiral blocks (Figure 1).

To start the polymerization of the first block, $7 \mathrm{c}$ or $\mathbf{7 d}$ is added to the functionalized initiator with the monomer/initiator ratio corresponding to the targeted length of the first block. For P3BTb-P3OT*, we opted for P3OT* as the first block for solubility reasons. The initially added monomer is fully consumed after $1 \mathrm{~h}$. Exploiting the living nature of the polymerization, the second monomer $(7 \mathbf{a}, 7 \mathbf{d}$, or $7 \mathbf{e})$ is added in such amount that the total chain length for all the polymers (block $\mathrm{A}+$ block $\mathrm{B}$ ) is the same (Scheme 4A and Table 2). After stirring overnight, the polymerization is terminated with a $2 \mathrm{M} \mathrm{HCl}$ solution, precipitated in methanol, and subjected to a Soxhlet extraction with methanol, acetone, hexane, and chloroform. The chloroform fraction is precipitated in methanol and dried. Termination with acid is preferred to avoid disproportionation, which would result in $\mathrm{BAB}$ block copolymers. ${ }^{10}$ The random copolymers were prepared by adding the two monomers in the appropriate ratio together at the beginning of the polymerization (Scheme 4B).
Table 2. Ratio of Monomers 7a, 7c, 7d, and $7 \mathrm{e}$ to the Initiator 8 Used in the Synthesis of the Corresponding Block and Random Copolymers

\begin{tabular}{|c|c|c|}
\hline polymer & $7 c / 8$ & $7 \mathrm{~d} / 8$ \\
\hline $\mathrm{P}_{30} \mathrm{~T}_{36}$ & 40 & 0 \\
\hline $\mathrm{P} \mathrm{OT}_{31}-b-\mathrm{P} \mathrm{OT}_{9}^{*}$ & 32 & 8 \\
\hline $\mathrm{P} \mathrm{OT}{ }_{19}-b-\mathrm{P} \mathrm{OT}^{*}{ }_{19}$ & 20 & 20 \\
\hline $\mathrm{P} \mathrm{OT}_{8}-b$-P3OT $_{30}$ & 8 & 32 \\
\hline $\mathrm{P3OT}_{38}{ }_{38}$ & 0 & 40 \\
\hline $\mathrm{P} \mathrm{OT}_{31}-\mathrm{co}-3 \mathrm{OT}_{10}^{*}$ & 32 & 8 \\
\hline $\mathrm{P} \mathrm{OT}_{20}-\mathrm{co}-\mathrm{OOT}_{18}^{*}$ & 20 & 20 \\
\hline $\mathrm{P} 3 \mathrm{OT}_{10^{-}} \mathrm{co}-3 \mathrm{OT}_{25}^{*}$ & 8 & 32 \\
\hline polymer & $7 a / 8$ & $7 \mathrm{~d} / 8$ \\
\hline $\mathrm{P}_{3 \mathrm{BT}}{ }_{41}$ & 40 & 0 \\
\hline $\mathrm{P} 3 \mathrm{BT}_{32}-b-\mathrm{P} \mathrm{OT}^{*}{ }_{9}$ & 32 & 8 \\
\hline $\mathrm{P}_{3 B T_{11}-b-\mathrm{P}} \mathrm{OT}_{24}^{*}$ & 20 & 20 \\
\hline $\mathrm{P}_{3 \mathrm{BT}}{ }_{10}-b-\mathrm{P}_{30}{ }_{30}$ & 8 & 32 \\
\hline $\mathrm{P}_{3 \mathrm{BT}}{ }_{29-c o-3 \mathrm{OT}}^{*}{ }_{11}$ & 32 & 8 \\
\hline $\mathrm{P} 3 \mathrm{BT}_{21}$-co-3OT*${ }_{17}$ & 20 & 20 \\
\hline $\mathrm{P} 3 \mathrm{BT}_{11}-$ co-3OT*${ }_{30}$ & 8 & 32 \\
\hline polymer & $7 c / 8$ & $7 e / 8$ \\
\hline $\mathrm{P} \mathrm{BT}^{*}{ }_{18}$ & 0 & 40 \\
\hline $\mathrm{P}_{30} \mathrm{~T}_{20}-b-\mathrm{P}_{3} \mathrm{BT}_{11}^{*}$ & 32 & 8 \\
\hline $\mathrm{P} \mathrm{OT}_{11}-b-\mathrm{P}_{3} \mathrm{BT}_{17}^{*}$ & 20 & 20 \\
\hline $\mathrm{P}_{3} \mathrm{OT}_{4}-b-\mathrm{P}_{3} \mathrm{BT}_{21}^{*}$ & 8 & 32 \\
\hline $\mathrm{P} \mathrm{OT}_{27}-\mathrm{co}-3 \mathrm{BT}_{9}^{*}$ & 32 & 8 \\
\hline $\mathrm{P} \mathrm{OT}_{17}-\mathrm{co}-3 \mathrm{BT}_{17}^{*}$ & 20 & 20 \\
\hline $\mathrm{P} \mathrm{OT}_{8}-\mathrm{co}-3 \mathrm{BT}^{*}{ }_{19}$ & 8 & 32 \\
\hline
\end{tabular}

${ }^{1} \mathrm{H}$ NMR spectroscopy is used to determine the length of both blocks. The total chain length can be obtained by the ratio of the methyl protons of the initiator (singlet) at $2.49 \mathrm{ppm}$ and the total integration of all signals of the $\alpha$-methylene protons $(2.83-2.78 \mathrm{ppm})$ 
Table 3. Overview of the number average molar mass $(\bar{M} \mathbf{n})$, polydisperisty index (PDI), the degree of polymerization $(N)$, the fraction achiral monomers and chiral monomers incorporated for the synthesized block- and random-copolymers

\begin{tabular}{|c|c|c|c|c|c|}
\hline polymer & $\bar{M}_{\mathrm{n}}\left(\mathrm{kg} \mathrm{mol}^{-1}\right)$ & PDI & $N$ & $7 \mathrm{c}(\%)$ & $7 \mathrm{~d}(\%)$ \\
\hline $\mathrm{P}_{30} \mathrm{~T}_{36}$ & 10.2 & 1.1 & 36 & 100 & 0 \\
\hline $\mathrm{P} \mathrm{OT}_{31}-b-\mathrm{P}_{3} \mathrm{OT}_{9}^{*}$ & 12.7 & 1.1 & 40 & 78 & 22 \\
\hline P3OT $_{19-b-\text { P3OT }^{*}}{ }_{19}$ & 11.5 & 1.2 & 38 & 49 & 51 \\
\hline $\mathrm{P} \mathrm{OT}{ }_{8}-b-\mathrm{P} \mathrm{OT}_{30}^{*}$ & 11.5 & 1.2 & 38 & 20 & 80 \\
\hline $\mathrm{P3OT}_{38}{ }_{38}$ & 12.2 & 1.2 & 38 & 0 & 100 \\
\hline $\mathrm{P} 3 \mathrm{OT}{ }_{31}-\mathrm{co}-3 \mathrm{OT}^{*}{ }_{10}$ & 12.8 & 1.1 & 41 & 76 & 24 \\
\hline $\mathrm{P} \mathrm{OT}_{20}-\mathrm{co}-3 \mathrm{OT}^{*}{ }_{18}$ & 11.0 & 1.1 & 38 & 52 & 48 \\
\hline $\mathrm{P} \mathrm{OT}_{10^{-c o}}-\mathrm{OOT}_{25}^{*}$ & 9.8 & 1.1 & 35 & 30 & 70 \\
\hline polymer & $\bar{M}_{\mathrm{n}}\left(\mathrm{kg} \mathrm{mol}^{-1}\right)$ & PDI & $N$ & $7 \mathbf{d}(\%)$ & $7 a(\%)$ \\
\hline $\mathrm{P}_{3 B T_{41}}$ & 8.6 & 1.2 & 41 & 0 & 100 \\
\hline $\mathrm{P}_{3 \mathrm{BT}}{ }_{32}-b-\mathrm{P} \mathrm{OT}{ }_{9}^{*}$ & 12.1 & 1.2 & 41 & 22 & 78 \\
\hline $\mathrm{P} 3 \mathrm{BT}_{11}-b-\mathrm{P} \mathrm{OT}_{24}^{*}$ & 7.2 & 1.1 & 35 & 68 & 32 \\
\hline $\mathrm{P}_{3 B T_{10}}-b-\mathrm{P}_{30}{ }_{30}$ & 9.8 & 1.1 & 40 & 75 & 25 \\
\hline $\mathrm{P}_{3 \mathrm{BT}}{ }_{29-c o-3 \mathrm{OT}^{*}}{ }_{11}$ & 11.6 & 1.1 & 40 & 28 & 72 \\
\hline 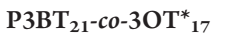 & 11.5 & 1.2 & 38 & 46 & 54 \\
\hline $\mathrm{P}_{3 B T_{11}-c o-3 \mathrm{OT}^{*}}{ }_{30}$ & 12.3 & 1.1 & 41 & 74 & 26 \\
\hline polymer & $\bar{M}_{\mathrm{n}}\left(\mathrm{kg} \mathrm{mol}^{-1}\right)$ & PDI & $N$ & $7 \mathrm{c}(\%)$ & $7 \mathbf{e}(\%)$ \\
\hline P3BT $_{18}{ }_{18}$ & 3.8 & 1.2 & 18 & 0 & 100 \\
\hline $\mathrm{P} \mathrm{OT}_{20^{-}} b-\mathrm{P}_{3} \mathrm{BT}^{*}{ }_{11}$ & 7.9 & 1.2 & 31 & 64 & 36 \\
\hline $\mathrm{P} \mathrm{OT}_{11}-b-\mathrm{P}_{3} \mathrm{BT}^{*}{ }_{17}$ & 5.5 & 1.2 & 28 & 38 & 62 \\
\hline $\mathrm{P}_{30 T}-b-\mathrm{P}_{3} \mathrm{BT}_{21}^{*}$ & 4.3 & 1.2 & 25 & 15 & 85 \\
\hline $\mathrm{P}_{3} \mathrm{OT}_{27}-\mathrm{co}-3 \mathrm{BT}_{9}^{*}$ & 8.1 & 1.2 & 36 & 75 & 25 \\
\hline $\mathrm{P}_{3} \mathrm{OT}_{17^{-c o}-3 \mathrm{BT}^{*}{ }_{17}}$ & 7.3 & 1.2 & 34 & 50 & 50 \\
\hline $\mathrm{P} 3 \mathrm{OT}{ }_{8}-\mathrm{co}-3 \mathrm{BT}^{*}{ }_{19}$ & 6.4 & 1.2 & 27 & 28 & 72 \\
\hline
\end{tabular}

(see Figures S4 and S5). The ratio of the ${ }^{1} \mathrm{H}$ NMR signal of the protons of the methyl group (s) of the branched chiral substituent, and the signal of the $\alpha$-methylene protons, allows an easy quantification of the achiral and the chiral monomers incorporated in the polymer. These two parameters provide us with the actual length of each block. These lengths, the relative amounts of each block, $\bar{M}_{\mathrm{n}}$ and PDI determined by GPC in THF toward polystyrene standards are listed in Table 3 for all the synthesized polymers. Note that the GPC results also confirm that the copolymers all have a similar molar mass and low PDI.

All the block copolymers were subjected to a solvatochromism experiment. For this purpose, nonsolvent was added gradually up to $56 \%$ methanol (see Supporting Information Figures S2 and S3). No change in the spectra was observed using a higher nonsolvent percentage. During these additions, UV-vis and circular dichroism (CD) spectra were recorded in order to verify whether two different species which would normally aggregate separately (at different nonsolvent content), but as a result of too rapid addition of nonsolvent would be forced to aggregate simultaneously. This was not the case. The same amount of nonsolvent was added to the random copolymers. The UV-vis and CD spectra are consistent with those of aggregated P3ATs (see Supporting Information Figures S2, S3, and S4). The results of the CD signals (i.e., $g_{\text {abs }}$ value, $g_{\text {abs }}=\Delta \varepsilon / \varepsilon$ ) under the final solvent conditions for the block and random copolymers are shown in Figure 4 as a function of their percentage chiral monomer. In the case of the
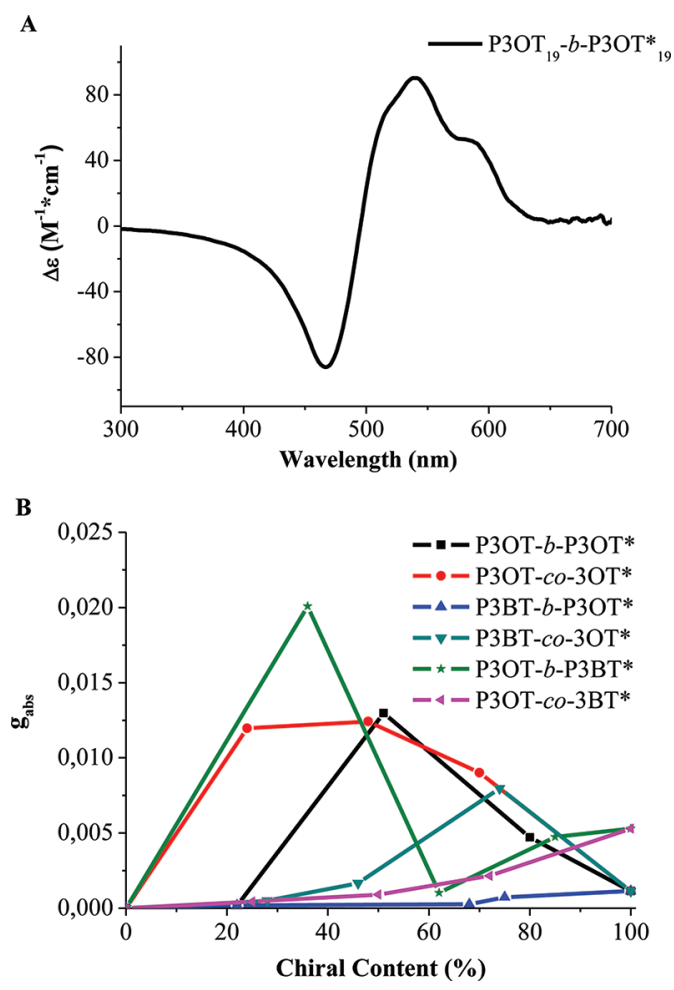

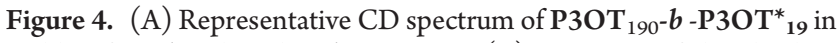
a chloroform/methanol 44/56 mixture. (B) Overview of the absolute value of $g$ values of the negative Cotton effect in $\mathrm{CD}$ spectroscopy for the block and random copolymers in a chloroform/methanol 44/56 mixture. The data points are calculated from the absolute values of the maximal CD signal near $470 \mathrm{~nm}$.

block copolymers, the two blocks aggregate separately if the solubility of both blocks is significantly different; in the random copolymers, such microphase separation is, of course, absent. If the first polymer of the P3OT-b-P3OT* series is considered $\left(\right.$ P3OT $_{31}-$ b-P3OT $\left._{9}^{*}\right)$, it is clear that it is composed of a short chiral block and a long, less soluble achiral block. As a consequence, the achiral block aggregates first. Naturally, as this block is achiral, the stacking of the this block is achiral; i.e., the polymer chains are parallel stacked. When the chiral block aggregates (at higher nonsolvent content), the stacking of this block is governed by the first block: both blocks adopt more or less the same orientation, and all polymer chains, also the part of the chiral block, are hardly rotated. Therefore, in the final solvent conditions, P3OT $_{31}-b-$ P3OT $_{9}{ }_{9}$ shows only a very small chiral responsemuch smaller than expected if both blocks would stack independently. In the other P3OT-b-P3OT* block copolymers, both blocks have more or less the same solubility, and they stack simultaneously. Since the side chains have an equal length, microphase separation is unlikely and both blocks stack together. If a sergeant-and-soldier behavior would be present, the chiral response should be higher than predicted by the mole ratio of chiral monomer but smaller than that of $\mathrm{P} \mathrm{OT}^{*}$ homopolymer. Interestingly, the chiral response of $\mathrm{P} \mathrm{OT}_{19}-b$-P3OT $^{*}{ }_{19}$ and $\mathrm{P} \mathrm{OT}_{\mathbf{8}}-\boldsymbol{b}-\mathrm{P} \mathrm{OT}^{*}{ }_{30}$ is much larger, pointing to the fact that this is no sergeant-and-soldiers behavior. This is rather remarkable since Meijer and co-workers reported sergeant-and-soldier behavior in blends of chiral and achiral P3ATs. ${ }^{51}$ Nonetheless, it is clear that in block copolymers of which both blocks stack together the 
chiral response is higher, meaning that the angle by which the stacked polymer chains are rotated is higher than in the chiral homopolymer. An analogous trend is also found in the random copolymers: the chiral response of $\mathrm{P}_{30} \mathrm{OT}_{31^{-}}$co-3OT ${ }^{*}{ }_{10}, \mathrm{P} \mathrm{OT}_{20^{-}}$ co-3OT ${ }_{18}$, and $\mathrm{P}^{3} \mathrm{OT}_{10}{ }^{-c o-3 O T}{ }^{*}{ }_{25}$ is higher than that of the homopolymer $\left(\right.$ P3OT $\left._{38}^{*}\right)$.

Let us consider the P3BT-b-P3OT* series next. In comparison with the achiral block of the previous series (P3OT), P3BT suffers from a poorer solubility. Note that this poor solubility made us to use P3OT* as the first block in the synthesis of the block copolymer. Precipitation of the P3BT block would terminate the polymerization, rendering block copolymer formation impossible. Therefore, in all P3BT-b-P3OT* block copolymers, the P3BT block aggregates first (in a achiral way). This hinders the chiral stacking of the P3OT* block: the chiral block is forced to adopt more or less the same stacking as the first block. This results in a smaller than expected chiral response. Interestingly, in (some of) the random copolymers, the chiral response again exceeds $g_{\text {abs }}$ of P3OT $^{*}{ }_{38}$.

Finally, the P3BT*-b-P3OT series is studied. In contrast to the previous block copolymers, here the chiral polymer has the lower solubility. Hence, in the block copolymers in which the chiral block has the same or a larger length than the achiral block, the chiral block aggregate first. Upon aggregation, the polymer chains of the second, achiral block are forced to stack in the same way, i.e., rotated toward each other. Therefore, the chiral response of $\mathrm{P}_{3} \mathrm{OT}^{*}{ }_{38}$ and $\mathrm{P}_{3} \mathrm{OT}_{11}-b-\mathrm{P}_{3} \mathrm{BT}^{*}{ }_{17}$ and $\mathrm{P}_{3} \mathrm{OT}_{4}-b$ $\mathbf{P} \mathrm{BT}^{*}{ }_{21}$ do not significantly differ. $\mathbf{P}_{30} \mathrm{~T}_{20}-b-\mathbf{P}_{3} \mathrm{BT}^{*}{ }_{21}$, in contrast, is composed of a short P3BT* and a long P3OT, of which the solubility is equal. They therefore aggregate simultaneously, and the block copolymer again shows a much higher $\mathrm{CD}$ effect. The random copolymers P3BT*-co-3OT, however, show in all cases a small chiral response than P3BT $^{*}{ }_{18}$, which contrasts to the other series of random copolymers.

In summary, two sets of materials can be distinguished: either block copolymers of which the blocks aggregate separately or random copolymers and block copolymers of which the blocks aggregate simultaneously. In the former polymers, the block aggregating first imposes its supramolecular structure to the second and as such determines the stacking behavior of the second as well. In the latter case, the chiral response can be much higher than that of the chiral homopolymer, despite the lower content of chiral moieties. Sergeant-and-soldiers behavior is in all cases absent, in both block copolymer and random copolymers.

It might seem surprising that the highest chiral response is not found in polymers with the highest content of chiral monomer. In this respect, it is instructive to consider the reason why a (bisignate) Cotton effect can be observed in chiral conjugated polymers. If the polymer is substituted with achiral (linear) alkyl groups, the polymer chains stack parallel, maximizing the $\pi$-interactions. If asymmetrically branched (chiral) side chains are employed, steric hindrance prevents a parallel stacking; instead the chains are slightly rotated. Note that the eventual organization is a compromise between $\pi$-interactions, which favor a close, parallel stacking, and steric hindrance, which results in a larger distance between and a rotation of the polymer chains. In case of random copolymers or block copolymers of which the blocks stack simultaneously, the packing of the chains cannot be as efficient as in the case of a homopolymer. Hence, one might assume that the distance between the chains becomes larger; i.e., the $\pi$-interactions are weakened. As a consequence, the branching of side chain can lead to a larger rotation of the stacked chains.
Since the twists remain moderate (i.e., $<45^{\circ}$ ), this results in stronger CD effects. ${ }^{11}$

\section{EXPERIMENTAL SECTION}

Reagents and Instrumentation. All reagents were purchased from Sigma-Aldrich, Acros Organics, Merck, and Alfa Aesar. Reagent grade solvents were dried by a solvent purification system MBRAUN SPS 800 (columns with activated alumina). Bromo-(o-tolyl)-bis(triphenylphosphine)nickel (8), ${ }^{12}$ the 2-bromo-3-alkylthiophenes $5 \mathbf{a}^{13}{ }^{13} \mathbf{5 b},{ }^{14} \mathbf{5 c},{ }^{14}$ and $5 \mathrm{e},{ }^{14}$ the precursor monomers $6 \mathbf{b}^{3 \mathrm{~b}}$ and $6 \mathbf{d},{ }^{5 \mathrm{~h}}$ and the bithiophene $3^{10}$ were prepared according to literature procedures. Before each polymerization, a small aliquot of 2-bromo-5-magnesiochloro-3alkylthiophene was quenched with $\mathrm{D}_{2} \mathrm{O}$ and analyzed by ${ }^{1} \mathrm{H}$ NMR to verify the quantitative conversion. Gel permeation chromatography (GPC) measurements were done with a Shimadzu 10A apparatus with a tunable absorbance detector and a differential refractometer in tetrahydrofuran as eluent toward polystyrene standards. Mass spectra were recorded using an Agilent HP5989. ${ }^{1} \mathrm{H}$ nuclear magnetic resonance ( ${ }^{1} \mathrm{H}$ NMR) measurements were carried out with a Bruker Avance 300, 400, and $600 \mathrm{MHz}$. UV-vis and CD measurements were performed on a Perkin-Elmer Lambda 900 UV-vis NIR and a JASCO 62 DS apparatus, respectively.

2-Bromo-3,4', 4"-trihexylterthiophene (4). A solution of 2,2,6,6-tetramethylpiperidine $(0.898 \mathrm{mmol}, 0.127 \mathrm{~g})$ in dry THF $(7.50 \mathrm{~mL})$ was cooled to $0^{\circ} \mathrm{C}$ and purged with argon. $n$-BuLi (2.50 M in hexane, 0.860 mmol, $0.340 \mathrm{~mL}$ ) was added to the solution, and the reaction was allowed to reach room temperature during $1 \mathrm{~h}$. Subsequently, the reaction was cooled to $0{ }^{\circ} \mathrm{C}$, and $\mathbf{1 b}(0.525 \mathrm{mmol}, 88.4 \mathrm{mg})$ in dry THF $(3 \mathrm{~mL})$ was added to the reaction mixture. After $90 \mathrm{~min}$ of stirring at $0{ }^{\circ} \mathrm{C}, \mathrm{Me}_{3} \mathrm{SnCl}(0.600 \mathrm{mmol}, 0.112 \mathrm{~g})$ in dry THF $(2.50 \mathrm{~mL})$ was added, and the reaction was allowed to reach room temperature over $90 \mathrm{~min}$.

Then, the bithiophene $3(1.00 \mathrm{mmol}, 0.492 \mathrm{~g})$ in dry THF $(2.50 \mathrm{~mL})$ was added to the in situ prepared stannylated compound 2. In a next step, the reaction mixture was added to $\mathrm{Pd}\left(\mathrm{PPh}_{3}\right)_{4}$, and the reaction was stirred overnight at $60{ }^{\circ} \mathrm{C}$. Then $\mathrm{H}_{2} \mathrm{O}$ was added, and the reaction mixture was extracted with $\mathrm{CH}_{2} \mathrm{Cl}_{2}$. The organic layer was washed with a saturated $\mathrm{NaHCO}_{3}$ solution, $\mathrm{NH}_{4} \mathrm{Cl}$ solution, and brine and subsequently dried with $\mathrm{MgSO}_{4}$ and concentrated under reduced pressure. The crude product was purified with column chromatography $\left(\mathrm{SiO}_{2}\right.$, petroleum ether), and $5 \mathrm{mg}$ of the crude product was subjected to recycling GPC. Yield: $26.6 \mathrm{mg}(9 \%) .{ }^{1} \mathrm{H}$ NMR $\left(\mathrm{CDCl}_{3}\right): \delta=6.95(\mathrm{~s}$, $1 \mathrm{H}), 6.91(\mathrm{~s}, 1 \mathrm{H}), 6.90(\mathrm{~s}, 1 \mathrm{H}), 6.84(\mathrm{~s}, 1 \mathrm{H}), 2.71(\mathrm{t}, 2 \mathrm{H}), 2.60(\mathrm{t}, 2 \mathrm{H})$, $2.53(\mathrm{t}, 2 \mathrm{H}), 1.53(\mathrm{~m}, 6 \mathrm{H}), 1.33(\mathrm{~m}, 18 \mathrm{H}), 0.90(\mathrm{~m}, 9 \mathrm{H}) .{ }^{13} \mathrm{C} \mathrm{NMR}$ $\left(\mathrm{CDCl}_{3}\right): \delta=143.7,142.9,140.0,136.7,135.4,134.1,130.3,127.2$, 126.4, 124.2, 120.1, 107.5, 32.6, 30.4, 29.3, 28.9, 22.6, 14.1. MS (CI): $579 / 581\left(\mathrm{MH}^{+}\right), 501\left(\mathrm{MH}^{+}-\mathrm{Br}\right)$.

2-Bromo-5-iodo-3-butylthiophene (6a). 2-Bromo-3-butylthiophene (5a) $(43.0 \mathrm{mmol}, 2.49 \mathrm{~g})$ was dissolved in dichloromethane $(250 \mathrm{~mL})$, shielded from light, and kept under argon atmosphere at $0{ }^{\circ} \mathrm{C}$. Iodobenzene diacetate $(18.0 \mathrm{mmol}, 58.0 \mathrm{~g})$ and iodine ( $16.6 \mathrm{mmol}, 4.22 \mathrm{~g}$ ) were added to the reaction mixture, and the solution was stirred during $4 \mathrm{~h}$ at room temperature. Afterward, the mixture was extracted with diethyl ether and washed with a $10 \% \mathrm{Na}_{2} \mathrm{~S}_{2} \mathrm{O}_{3}$ solution. The organic layer was dried with $\mathrm{MgSO}_{4}$, and the solution was concentrated. The crude product was heated under reduced pressure during $3 \mathrm{~h}$ to remove the iodobenzene. Subsequently, the product was dissolved in diethyl ether and activated carbon was added. Afterward, the product was filtered, concentrated, and purified by vacuum distillation $\left(85^{\circ} \mathrm{C}, 0.025 \mathrm{mmHg}\right)$, and a pale yellow oil was obtained. Yield: $8.11 \mathrm{~g}(55 \%) .{ }^{1} \mathrm{H} \mathrm{NMR}\left(\mathrm{CDCl}_{3}\right): \delta=6.96(\mathrm{~s}, 1 \mathrm{H})$, $2.53(\mathrm{t}, 2 \mathrm{H}), 1.53(\mathrm{~m}, 2 \mathrm{H}), 1.34(\mathrm{~m}, 2 \mathrm{H}), 0.93(\mathrm{t}, 3 \mathrm{H}) .{ }^{13} \mathrm{C} \mathrm{NMR}$ $\left(\mathrm{CDCl}_{3}\right): \delta=144.2,138.0,111.7,71.0,31.8,28.9,22.2$, 13.8. MS (EI): $343 / 346\left(\mathrm{M}^{\bullet+}\right)$. 
2-Bromo-5-iodo-3-octylhiophene $(\mathbf{6 c})$. The same procedure as described for 6 a was followed, using 2-bromo-3-octylthiophene $(5 \mathrm{c})$ ( $24.5 \mathrm{mmol}, 6.73 \mathrm{~g})$, iodobenzene diacetate $(14.7 \mathrm{mmol}, 4.73 \mathrm{~g})$, and iodine $(13.6 \mathrm{mmol}, 3.44 \mathrm{~g})$. The resulting pure product after vacuum distillation $\left(152{ }^{\circ} \mathrm{C}, 0.5 \mathrm{mmHg}\right)$ was a pale yellow oil. Yield: $5.89 \mathrm{~g}$ $(60 \%) .{ }^{1} \mathrm{H} \mathrm{NMR}\left(\mathrm{CDCl}_{3}\right): \delta=6.96(\mathrm{~s}, 1 \mathrm{H}), 2.52(\mathrm{t}, 2 \mathrm{H}), 1.54(\mathrm{~m}, 2 \mathrm{H})$, $1.29(\mathrm{~m}, 10 \mathrm{H}), 0.88(\mathrm{t}, 3 \mathrm{H}) .{ }^{13} \mathrm{C}$ NMR $\left(\mathrm{CDCl}_{3}\right): \delta=144.3,138.0$, $111.7,71.0,31.9,29.7,29.3,29.3,29.2,29.2,29.1,22.7,14.1$. MS (EI): $400 / 402\left(\mathrm{M}^{\circ+}\right)$.

2-Bromo-5-iodo-3-(2-methylbutylthiophene) (6e). The same procedure as described for $\mathbf{6 a}$ was followed, using 2-bromo-3-(2-methylbutylthiophene) (5e) (66.4 mmol, $15.5 \mathrm{~g})$, iodobenzene diacetate (35.0 $\mathrm{mmol}, 11.28 \mathrm{~g})$, and iodine $(34.0 \mathrm{mmol}, 8.62 \mathrm{~g})$. The resulting pure product after vacuum distillation $\left(68^{\circ} \mathrm{C}, 2 \mathrm{mmHg}\right)$ was a pale yellow oil. Yield: $18.94 \mathrm{~g}(79.5 \%) .{ }^{1} \mathrm{H} \mathrm{NMR}\left(\mathrm{CDCl}_{3}\right): \delta=6.92(\mathrm{~s}, 1 \mathrm{H}), 2.56-2.49$ (dd, $1 \mathrm{H}), 2.36-2.29(\mathrm{dd}, 1 \mathrm{H}), 1.64-1.62(\mathrm{~m}, 1 \mathrm{H}), 1.38-1.35(\mathrm{~m}, 1 \mathrm{H})$, $1.20-1.15(\mathrm{~m}, 1 \mathrm{H}), 0.93-0.85(\mathrm{~m}, 6 \mathrm{H}) .{ }^{13} \mathrm{CNMR}\left(\mathrm{CDCl}_{3}\right): \delta=145.5$, 140.7, 114.6, 73.2, 38.4, 37.9, 31.4, 21.2, 13.7. MS (EI): 360/358 $\left(\mathrm{MH}^{+}\right)$.

General Procedure for the Preparation of the Monomers $7 \mathrm{a}-7 \mathrm{e}$. The precursor monomers $6 \mathrm{a}-6 \mathrm{e}(10.0 \mathrm{mmol})$ were dissolved in dry THF $(66.7 \mathrm{~mL})$ and purged with argon. $i-\mathrm{PrMgCl} . \mathrm{LiCl}(1.22 \mathrm{M}$ in THF; $10.0 \mathrm{mmol}, 8.21 \mathrm{~mL}$ ) was added to the solution, and the reaction was stirred during $15 \mathrm{~min}$ at $40{ }^{\circ} \mathrm{C}$ and another $45 \mathrm{~min}$ at room temperature. The conversion of the GRIM reaction was evaluated by pouring an aliquot of the reaction mixture in $\mathrm{D}_{2} \mathrm{O}$ and analyzing it with ${ }^{1} \mathrm{H}$ NMR spectroscopy.

General Procedure for the Polymerization of the Homopolymers $\mathrm{P}_{3} \mathrm{HT}_{13,18,20,24,27,30}$ and $\mathrm{P}_{3} \mathrm{OT}_{12,18,22,29}$. The monomers $7 \mathbf{b}$ and $7 \mathbf{c}$ were added to a suspension of $\mathrm{Ni}(\mathrm{dppp}) \mathrm{Cl}_{2}$ in dry THF $(6 \mathrm{~mL})$ under an argon atmosphere. After $1 \mathrm{~h}$, the reaction mixture was quenched with a $2 \mathrm{M} \mathrm{HCl}$ solution, precipitated in methanol, filtered, and dried under vacuum. The final polymer was a dark red-brown solid. For the synthesis of all the $\mathbf{P}_{3} \mathbf{H T}_{x}$ and $\mathbf{P}^{30} \mathbf{T}_{x}$ polymers, the general procedure was performed.

Synthesis of $\boldsymbol{P 3 H T}_{\mathbf{1 3}}$. The used reagents were $7 \mathbf{b}(0.13 \mathrm{mmol} / \mathrm{mL}$ in THF, $1 \mathrm{mmol}, 7.50 \mathrm{~mL})$ and $\mathrm{Ni}(\mathrm{dppp}) \mathrm{Cl}_{2}(66.7 \mu \mathrm{mol}, 36.3 \mathrm{mg})$. Yield: $142 \mathrm{mg}(86 \%)$.

Synthesis of $\boldsymbol{P} \mathbf{3} \boldsymbol{H T}_{\mathbf{1 8}}$. The used reagents were $7 \mathbf{b}(0.13 \mathrm{mmol} / \mathrm{mL}$ in THF, $1 \mathrm{mmol}, 7.50 \mathrm{~mL})$ and $\mathrm{Ni}(\mathrm{dppp}) \mathrm{Cl}_{2}(50.0 \mu \mathrm{mol}, 27.1 \mathrm{mg})$. Yield: $147 \mathrm{mg}(89 \%)$.

Synthesis of $\mathbf{P} \mathbf{3} \mathbf{T}_{\mathbf{2 0}}$. The used reagents were $7 \mathbf{b}(0.13 \mathrm{mmol} / \mathrm{mL}$ in THF, $1 \mathrm{mmol}, 7.50 \mathrm{~mL})$ and $\mathrm{Ni}(\mathrm{dppp}) \mathrm{Cl}_{2}(40.0 \mu \mathrm{mol}, 21.7 \mathrm{mg})$. Yield: $151 \mathrm{mg}(91 \%)$.

Synthesis of $\mathbf{P} \mathbf{3} \boldsymbol{T}_{\mathbf{2 4}}$. The used reagents were $7 \mathbf{b}(0.13 \mathrm{mmol} / \mathrm{mL}$ in THF, $1 \mathrm{mmol}, 7.50 \mathrm{~mL})$ and $\mathrm{Ni}(\mathrm{dppp}) \mathrm{Cl}_{2}(33.3 \mu \mathrm{mol}, 18.1 \mathrm{mg})$. Yield: $144 \mathrm{mg}$ (93\%).

Synthesis of $\boldsymbol{P 3}_{\mathbf{H}} \boldsymbol{T}_{\mathbf{2 7}}$. The used reagents were $7 \mathbf{b}(0.13 \mathrm{mmol} / \mathrm{mL}$ in THF, $1 \mathrm{mmol}, 7.50 \mathrm{~mL})$ and $\mathrm{Ni}(\mathrm{dppp}) \mathrm{Cl}_{2}(28.6 \mu \mathrm{mol}, 15.5 \mathrm{mg})$. Yield: $157 \mathrm{mg}(94 \%)$.

Synthesis of $\mathbf{P 3 O T}_{\mathbf{1 2}}$. The used reagents were $7 \mathrm{c}(0.13 \mathrm{mmol} / \mathrm{mL}$ in THF, $1 \mathrm{mmol}, 7.50 \mathrm{~mL})$ and $\mathrm{Ni}(\mathrm{dppp}) \mathrm{Cl}_{2}(66.7 \mu \mathrm{mol}, 36.3 \mathrm{mg})$. Yield: $166 \mathrm{mg}(86 \%)$.

Synthesis of $\mathbf{P 3 O T}_{\mathbf{1 8}}$. The used reagents were $7 \mathrm{c}(0.13 \mathrm{mmol} / \mathrm{mL}$ in THF, $1 \mathrm{mmol}, 7.50 \mathrm{~mL})$ and $\mathrm{Ni}(\mathrm{dppp}) \mathrm{Cl}_{2}(50.0 \mu \mathrm{mol}, 27.1 \mathrm{mg})$. Yield: $177 \mathrm{mg}(91 \%)$.

Synthesis of $\mathbf{P 3 O T}_{\mathbf{2 2}}$. The used reagents were $7 \mathrm{c}(0.13 \mathrm{mmol} / \mathrm{mL}$ in THF, $1 \mathrm{mmol}, 7.50 \mathrm{~mL})$ and $\mathrm{Ni}(\mathrm{dppp}) \mathrm{Cl}_{2}(33.3 \mu \mathrm{mol}, 18.1 \mathrm{mg})$. Yield: $188 \mathrm{mg}(97 \%)$.

Synthesis of $\mathbf{P 3 O T}_{\mathbf{2 9}}$. The used reagents were $7 \mathrm{c}(0.13 \mathrm{mmol} / \mathrm{mL}$ in THF, $1 \mathrm{mmol}, 7.50 \mathrm{~mL})$ and $\mathrm{Ni}(\mathrm{dppp}) \mathrm{Cl}_{2}(28.6 \mu \mathrm{mol}, 15.5 \mathrm{mg})$. Yield: $162 \mathrm{mg}(94 \%)$.

General Procedure for the Polymerization of the Homopolymers $\mathrm{P}_{3 \mathrm{BT}}{ }_{41}, \mathrm{P}_{30} \mathrm{OT}_{36}, \mathrm{P}_{30 T}{ }_{38}$, and $\mathrm{P}_{3} \mathrm{BT}_{18}{ }^{*}$. The initiator $8(25.0 \mu \mathrm{mol}, 18.9 \mathrm{mg})$ and dppp $(50.0 \mu \mathrm{mol}, 20.6 \mathrm{mg})$ were dissolved dry in THF $(6.60 \mathrm{~mL})$ and stirred for $30 \mathrm{~min}$ at room temperature and under an argon atmosphere. In the next step, the monomer $7 \mathrm{a}, 7 \mathrm{c}, 7 \mathrm{~d}$, or $7 \mathrm{e}$ was added to the solution, and the mixture was allowed to react overnight. Afterward, the polymerization was quenched with a $2 \mathrm{M} \mathrm{HCl}$ solution and precipitated in methanol. Next, the polymer was filtered off and fractionated by Soxhlet extraction with methanol, acetone, and chloroform. The chloroform-soluble fraction was precipitated in methanol, filtered, and dried in vacuo. The final polymer was a dark red-brown solid. For the synthesis of all the homopolymers, the general procedure was performed.

Synthesis of $\boldsymbol{P B B T}_{\mathbf{4 1}}$. The used monomer was $7 \mathbf{a}(0.11 \mathrm{mmol} / \mathrm{mL}$ in THF, $1.00 \mathrm{mmol}, 9.13 \mathrm{~mL})$. Yield: $132 \mathrm{mg}(65 \%)$.

Synthesis of $\mathbf{P 3 O T}_{\mathbf{3 6}}$. The used monomer was $7 \mathrm{c}(0.11 \mathrm{mmol} / \mathrm{mL}$ in THF, $1.00 \mathrm{mmol}, 9.13 \mathrm{~mL})$. Yield: $149 \mathrm{mg}(76 \%)$.

Synthesis of $\mathbf{P 3 O T}^{*}{ }_{\mathbf{3 8}}$. The used monomer was $7 \mathbf{d}(0.11 \mathrm{mmol} / \mathrm{mL}$ in THF, $1.00 \mathrm{mmol}, 9.13 \mathrm{~mL})$. Yield: $148 \mathrm{mg}(66 \%)$.

Synthesis of $\mathbf{P B B T}^{*}{ }_{1 \mathbf{8}}$. The used monomer was $7 \mathbf{e}(0.11 \mathrm{mmol} / \mathrm{mL}$ in THF, $1.00 \mathrm{mmol}, 9.13 \mathrm{~mL})$. Yield: $27.3 \mathrm{mg}(20 \%)$.

General Procedure for the Polymerization of the Block Copolymers $\mathrm{P} \mathrm{OT}_{n^{-}}-b-\mathrm{P} \mathrm{OT}{ }^{*}{ }_{m}, \mathrm{P} \mathrm{BT}_{m}-b-\mathrm{P} \mathrm{OT}^{*}{ }_{n}$, and P3OT $_{n^{-}}$ b-P3BT ${ }_{m}^{*}$. First, the initiator $8(25.0 \mu \mathrm{mol}, 18.9 \mathrm{mg})$ and dppp $(50.0$ $\mu \mathrm{mol}, 20.6 \mathrm{mg})$ were dissolved dry in THF $(6.60 \mathrm{~mL})$ and stirred for $30 \mathrm{~min}$ at room temperature and under an argon atmosphere. In a next step, the monomer $7 \mathrm{c}$ or $7 \mathbf{d}$ was added to the solution, and the mixture was allowed to react for $1 \mathrm{~h}$ at room temperature. Subsequently, the second monomer, $7 \mathrm{~d}, 7 \mathrm{a}$, or $7 \mathrm{e}$, was added, and the reaction mixture was stirred for $1.5 \mathrm{~h}$ at $30{ }^{\circ} \mathrm{C}$ and overnight at room temperature. Afterward, the polymerization was quenched with a $2 \mathrm{M} \mathrm{HCl}$ solution and precipitated in methanol. Next, the polymer was filtered and fractionated by Soxhlet extraction with methanol, acetone, and chloroform. The chloroformsoluble fraction was precipitated in methanol, filtered, and dried in vacuo. The final polymer was a dark red-brown solid. For the synthesis of all the block copolymers, the general procedure was performed.

Synthesis of $\mathbf{P 3 O T}_{\mathbf{3}} \mathbf{-} \boldsymbol{b}-\mathbf{P 3 O T}^{*}{ }_{\boldsymbol{9}}$. The used monomer in the first step was $7 \mathrm{c}(0.11 \mathrm{mmol} / \mathrm{mL}$ in THF, $0.800 \mathrm{mmol}, 7.31 \mathrm{~mL})$ and in the second step was $7 \mathrm{~d}(0.11 \mathrm{mmol} / \mathrm{mL}$ in THF, $0.200 \mathrm{mmol}, 1.83 \mathrm{~mL})$. Yield: $167 \mathrm{mg}(83 \%)$.

Synthesis of $\mathbf{P 3 O T}_{\mathbf{1 9}} \mathbf{- b}-\mathbf{P B O T}^{*}{ }_{1 \mathbf{9}}$. The used monomer in the first step was $7 \mathrm{c}(0.11 \mathrm{mmol} / \mathrm{mL}$ in THF, $0.500 \mathrm{mmol}, 4.56 \mathrm{~mL})$ and in the second step was $7 \mathrm{~d}(0.11 \mathrm{mmol} / \mathrm{mL}$ in THF, $0.500 \mathrm{mmol}, 4.56 \mathrm{~mL})$. Yield: $134 \mathrm{mg}(64 \%)$.

Synthesis of $\mathbf{P 3 O T}_{\mathbf{8}} \mathbf{-} \boldsymbol{b}-\mathbf{P} \mathbf{3 O T}{ }^{*}{ }_{\mathbf{3 0}}$. The used monomer in the first step was $7 \mathrm{c}(0.11 \mathrm{mmol} / \mathrm{mL}$ in THF, $0.200 \mathrm{mmol}, 1.83 \mathrm{~mL})$ and in the second step was $7 \mathbf{d}(0.11 \mathrm{mmol} / \mathrm{mL}$ in THF, $0.800 \mathrm{mmol}, 7.31 \mathrm{~mL})$. Yield: $152 \mathrm{mg}(70 \%)$.

Synthesis of $\mathbf{P 3 B T}_{\mathbf{3 2}}-\boldsymbol{b}-\mathbf{P 3 O T}^{*}$. The used monomer in the first step was $7 \mathrm{~d}(0.11 \mathrm{mmol} / \mathrm{mL}$ in THF, $0.750 \mathrm{mmol}, 6.85 \mathrm{~mL})$ and in the second step was $7 \mathrm{a}(0.11 \mathrm{mmol} / \mathrm{mL}$ in THF, $0.250 \mathrm{mmol}, 2.28 \mathrm{~mL})$. Yield: $85 \mathrm{mg}(61 \%)$.

Synthesis of $\mathbf{P} \mathbf{3} \mathbf{T T}_{\mathbf{1 1}}-\boldsymbol{b}-\mathbf{P} \mathbf{3 O T}{ }^{*}{ }_{\mathbf{2 4}}$. The used monomer in the first step was $7 \mathbf{d}(0.11 \mathrm{mmol} / \mathrm{mL}$ in THF, $0.500 \mathrm{mmol}, 4.56 \mathrm{~mL})$ and in the second step was $7 \mathrm{a}(0.11 \mathrm{mmol} / \mathrm{mL}$ in THF, $0.500 \mathrm{mmol}, 4.56 \mathrm{~mL})$. Yield: $99 \mathrm{mg}(63 \%)$.

Synthesis of $\mathbf{P} \mathbf{3} \mathbf{B T}_{\mathbf{1 0}}-\boldsymbol{b}-\mathbf{P 3 O T}^{*}{ }_{\mathbf{3 0}}$. The used monomer in the first step was $7 \mathbf{d}(0.11 \mathrm{mmol} / \mathrm{mL}$ in THF, $0.250 \mathrm{mmol}, 2.28 \mathrm{~mL})$ and in the second step was $7 \mathrm{a}(0.11 \mathrm{mmol} / \mathrm{mL}$ in THF, $0.750 \mathrm{mmol}, 6.85 \mathrm{~mL})$. Yield: $145 \mathrm{mg}(74 \%)$.

Synthesis of $\mathbf{P 3 O T}_{\mathbf{2 0}} \mathbf{- b}-\mathbf{P} \mathbf{B} \mathbf{B T}{ }^{*}{ }_{\mathbf{1 1}}$. The used monomer in the first step was $7 \mathrm{c}(0.11 \mathrm{mmol} / \mathrm{mL}$ in THF, $0.750 \mathrm{mmol}, 6.85 \mathrm{~mL})$ and in the second step was $7 \mathrm{e}(0.11 \mathrm{mmol} / \mathrm{mL}$ in THF, $0.250 \mathrm{mmol}, 2.28 \mathrm{~mL})$. Yield: $47 \mathrm{mg}$ (29\%).

Synthesis of $\mathbf{P 3 O T}_{\mathbf{1 1}}-\boldsymbol{b}-\mathbf{P B B T}^{*}{ }_{\mathbf{1 7}}$. The used monomer in the first step was $7 \mathrm{c}(0.11 \mathrm{mmol} / \mathrm{mL}$ in THF, $0.500 \mathrm{mmol}, 4.56 \mathrm{~mL})$ and in the second step was $7 \mathrm{e}(0.11 \mathrm{mmol} / \mathrm{mL}$ in THF, $0.500 \mathrm{mmol}, 4.56 \mathrm{~mL})$. Yield: $55 \mathrm{mg}$ (35\%). 
Synthesis of $\mathbf{P 3 O T}_{\mathbf{4}} \mathbf{- b}-\mathbf{P} \mathbf{3} \mathbf{B T}^{*}{ }_{21}$. The used monomer in the first step was $7 \mathrm{c}(0.11 \mathrm{mmol} / \mathrm{mL}$ in THF, $0.250 \mathrm{mmol}, 2.28 \mathrm{~mL})$ and in the second step was $7 \mathrm{e}(0.11 \mathrm{mmol} / \mathrm{mL}$ in THF, $0.750 \mathrm{mmol}, 6.85 \mathrm{~mL})$. Yield: $95 \mathrm{mg}(62 \%)$.

General Procedure for the Polymerization of the Random

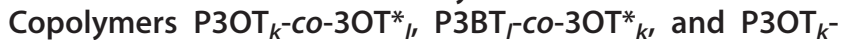

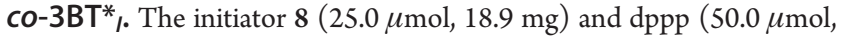
$20.6 \mathrm{mg})$ were dissolved dry in THF $(6.60 \mathrm{~mL})$ and stirred for $30 \mathrm{~min}$ at room temperature and under an argon atmosphere. Next, the two monomers $7 \mathrm{c}$ and $7 \mathrm{~d}, 7 \mathrm{a}$ and $7 \mathrm{~d}$, or $7 \mathrm{c}$ and $7 \mathrm{e}$ were loaded together to the initiator and were allowed to react overnight. Afterward, the polymerization was quenched with a $2 \mathrm{M} \mathrm{HCl}$ solution and precipitated in methanol. Next, the polymer was filtrated and fractionated by Soxhlet extraction with methanol, acetone, and chloroform. The chloroformsoluble fraction was precipitated in methanol, filtered off, and dried in vacuo. The final polymer was a dark red-brown solid. For the synthesis of all the random copolymers, the general procedure was performed.

Synthesis of $\mathbf{P 3 O T}_{\mathbf{3 1}}$-Co-30T* ${ }^{*}$. The used monomers were $7 \mathrm{c}$ $(0.11 \mathrm{mmol} / \mathrm{mL}$ in THF, $0.750 \mathrm{mmol}, 6.85 \mathrm{~mL})$ and $7 \mathrm{~d}(0.11 \mathrm{mmol} /$ $\mathrm{mL}$ in THF, $0.250 \mathrm{mmol}, 2.28 \mathrm{~mL})$. Yield: $146 \mathrm{mg}(72 \%)$.

Synthesis of $\mathbf{P 3 O T}_{\mathbf{2 0}}$-Co-30T* ${ }^{*}$. The used monomers were $7 \mathrm{c}$ $(0.11 \mathrm{mmol} / \mathrm{mL}$ in THF, $0.500 \mathrm{mmol}, 4.56 \mathrm{~mL})$ and $7 \mathrm{~d}(0.11 \mathrm{mmol} /$ $\mathrm{mL}$ in THF, $0.500 \mathrm{mmol}, 4.56 \mathrm{~mL})$. Yield: $142 \mathrm{mg}(68 \%)$.

Synthesis of $\mathbf{P 3 O T}_{\mathbf{1 0}}$-Co-3OT $^{*}{ }_{\mathbf{2 5}}$. The used monomers were $7 \mathrm{c}$ $(0.11 \mathrm{mmol} / \mathrm{mL}$ in THF, $0.250 \mathrm{mmol}, 2.28 \mathrm{~mL})$ and $7 \mathrm{~d}(0.11 \mathrm{mmol} /$ $\mathrm{mL}$ in THF, $0.750 \mathrm{mmol}, 0.750 \mathrm{~mL})$. Yield: $163 \mathrm{mg}(76 \%)$.

Synthesis of $\mathbf{P 3 B T}_{\mathbf{2 9}}$-co-30T ${ }^{*}{ }_{11}$. The used monomers were $\mathbf{7 a}(0.11$ $\mathrm{mmol} / \mathrm{mL}$ in THF, $0.750 \mathrm{mmol}, 6.85 \mathrm{~mL})$ and $7 \mathrm{~d}(0.11 \mathrm{mmol} / \mathrm{mL}$ in THF, $0.250 \mathrm{mmol}, 2.28 \mathrm{~mL})$. Yield: $94 \mathrm{mg}(58 \%)$.

Synthesis of $\mathbf{P} \mathbf{3} \mathbf{B T}_{\mathbf{2 1}}$-CO-30T* ${ }^{*}$. The used monomers were $\mathbf{7 a}(0.11$ $\mathrm{mmol} / \mathrm{mL}$ in THF, $0.500 \mathrm{mmol}, 4.56 \mathrm{~mL})$ and $7 \mathrm{~d}(0.11 \mathrm{mmol} / \mathrm{mL}$ in THF, $0.500 \mathrm{mmol}, 4.56 \mathrm{~mL})$. Yield: $112 \mathrm{mg}(63 \%)$.

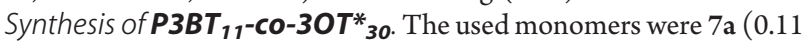
$\mathrm{mmol} / \mathrm{mL}$ in THF, $0.250 \mathrm{mmol}, 2.28 \mathrm{~mL})$ and $7 \mathrm{~d}(0.11 \mathrm{mmol} / \mathrm{mL}$ in THF, $0.750 \mathrm{mmol}, 6.85 \mathrm{~mL})$. Yield: $137 \mathrm{mg}(68 \%)$.

Synthesis of $\mathbf{P 3 O T}_{\mathbf{2 7}}-\mathbf{C O}_{\mathbf{3}} \mathbf{3} \mathbf{B T}_{\mathbf{9}}$. The used monomers were $\mathbf{7 c}(0.11$ $\mathrm{mmol} / \mathrm{mL}$ in THF, $0.750 \mathrm{mmol}, 6.85 \mathrm{~mL})$ and $7 \mathrm{e}(0.11 \mathrm{mmol} / \mathrm{mL}$ in THF, $0.250 \mathrm{mmol}, 2.28 \mathrm{~mL})$. Yield: $49 \mathrm{mg}$ (30\%).

Synthesis of $\mathbf{P 3 O T}_{17}$-CO-3BT ${ }^{*}$ 17. The used monomers were $7 \mathrm{c}(0.11$ $\mathrm{mmol} / \mathrm{mL}$ in THF, $0.500 \mathrm{mmol}, 4.56 \mathrm{~mL})$ and $7 \mathrm{e}(0.11 \mathrm{mmol} / \mathrm{mL}$ in THF, $0.500 \mathrm{mmol}, 4.56 \mathrm{~mL})$. Yield: $11 \mathrm{mg}(31 \%)$.

Synthesis of $\mathbf{P 3 O T}_{\mathbf{8}}$-Co-3BT ${ }^{*}$ 19. The used monomers were $7 \mathbf{c}(0.11$ $\mathrm{mmol} / \mathrm{mL}$ in THF, $0.250 \mathrm{mmol}, 2.28 \mathrm{~mL})$ and $7 \mathrm{e}(0.11 \mathrm{mmol} / \mathrm{mL}$ in THF, $0.750 \mathrm{mmol}, 6.85 \mathrm{~mL})$. Yield: $11 \mathrm{mg}(7 \%)$.

\section{CONCLUSIONS}

First, the synthesis of AB-type block copolymers was investigated. Using relative integration of all end-groups, it was found that the stickiness parameter $\delta$ of P3AT amounts $\sim 0.7$, which means that growth can occur on both sides of a growing P3AT chain if the polymerization is initiated by $\mathrm{Ni}(\mathrm{dppp}) \mathrm{Cl}_{2}$. Consequently, if copolymers are prepared by successive monomer addition, both $\mathrm{AB}$ - and $\mathrm{BAB}$-type polymers are formed. The exclusive formation of $A B$-type polymers requires the use of a functional $\mathrm{Ni}$ initiator which allows only growth on one side.

Second, the chiroptical behavior of the AB block copoly(3alkylthiophene)s, of which one block is chiral, was studied. It was shown that if the two blocks aggregate at different nonsolvent content, the block aggregating first determines the stacking behavior of the second as well. If not, the stacking of the blocks of the copolymer chains containing chiral and achiral monomers can result in a higher Cotton effect than the chiral homopolymer, as was also found for random copolymers. This is probably due to the irregular molecular structure of the copolymers, which complicates a closely stacked structure, resulting in a larger twist than that of the (regular) chiral homopolymer. Sergeant-andsoldiers behavior is in all these materials absent.

\section{ASSOCIATED CONTENT}

S Supporting Information. Probability of AB-block-copolymers in function of the length of block A and block B; the UV-vis and CD spectra of the block and random copolymers; the ${ }^{1} \mathrm{H}$ NMR and ${ }^{13} \mathrm{C}$ NMR characterizations of all new compounds; and all the ${ }^{1} \mathrm{H}$ NMR spectra of all the homopolymers and copolymers. This material is available free of charge via the Internet at http://pubs.acs.org.

\section{AUTHOR INFORMATION}

\section{Corresponding Author}

*E-mail: guy.koeckelberghs@chem.kuleuven.be.

\section{ACKNOWLEDGMENT}

We are grateful to the Onderzoeksfonds K.U.Leuven/Research Fund K.U.Leuven and the Fund for Scientific Research (FWO-Vlaanderen) for financial support. M.V. is a doctoral fellow of the Fund for Scientific Research (FWO-Vlaanderen). We are also grateful to Karel Duerinckx for the help and technical support with NMR spectroscopy.

\section{REFERENCES}

(1) (a) Garcia-Alvarez, J. L. Curr. Org. Chem. 2008, 12, 1199-1219. (b) Yokozawa, T.; Yokoyama, A. Chem. Rev. 2009, 109, 5595-55619. (c) Cheng, Y.; Yang, S.; Hsu, C. Chem. Rev. 2009, 109, 5868-5923. (d) Topham, P. D.; Parnell, A. J.; Hiorns, R. C. J. Polym. Sci., Part B: Polym. Phys. 2010, 49, 1131-1156. (e) Cuendias, A.; Hiorns, R. C.; Cloutet, E.; Vignau, L.; Cramail, H. Polym. Int. 2010, 59, 1452-1476. (f) Kiriy, A.; Senkovskyy, V.; Sommer, M. Macromol. Rapid Commun. 2011, 32, 1503-1517. (g) Operamolla, A.; Farinola, G. M. Eur. J. Org. Chem. 2011, $423-450$.

(2) (a) Iovu, M. C.; Sheina, E. E.; Gil, R. R.; McCullough, R. D. Macromolecules 2005, 38, 8649-8656. (b) Sheina, E. E.; Liu, J.; Iovu, M. C.; Laird, D. W.; McCullough, R. D. Macromolecules 2004, 37, 3526-3528.

(3) (a) Miyakoshi, R.; Yokoyama, A.; Yokozawa, T. J. Am. Chem. Soc. 2005, 127, 17542-17547. (b) Yokoyama, A.; Miyakoshi, R.; Yokozawa, T. Macromolecules 2004, 37, 1169-1171.

(4) (a) Huang, L.; Wu, S.; Qu, Y.; Geng, Y.; Wang, F. Macromolecules 2008, 41, 8944-8947. (b) Stefan, M. C.; Javier, A. E.; Osaka, I.; McCullough, R. D. Macromolecules 2009, 42, 30-32. (c) Adachi, I.; Miyakoshi, A.; Yokoyama, A.; Yokozawa, T. Macromolecules 2006, 39, 7793-7795. (d) Wu, S.; Sun, Y.; Huang, L.; Wang, J.; Zhou, Y.; Geng, Y.; Wang, F. Macromolecules 2010, 43, 4438-4440. (e) Vallat, P.; Lamps, J.-P.; Schosseler, F.; Rawiso, M.; Catala, J.-M. Macromolecules 2007, 40, 2600-2602. (f) Yokoyama, A.; Kato, A.; Miyakoshi, R.; Yokozawa, T. Macromolecules 2008, 41, 7271-7273. (g) Beryozkina, T.; Senkovskyy, V.; Kaul, E.; Kiriy, A. Macromolecules 2008, 41, 7817-2823. (h) Koeckelberghs, G.; Vangheluwe, M.; Samyn, C.; Persoons, A.; Verbiest, T. Macromolecules 2005, 38, 5554-5559. (i) Koeckelberghs, G.; Vangheluwe, M.; Van Doorsselaere, K.; Robijns, E.; Persoons, A.; Verbiest, T. Macromol. Rapid Commun. 2006, 27, 19201925. (j) Sheina, E. E. S.; Khersonsky, S. M.; Jones, E. G.; McCullough, R. D. Chem. Mater. 2005, 17, 3317-3319. (k) Van den Bergh, K.; De Winter, J.; Gerbaux, P.; Verbiest, T.; Koeckelberghs, G. Macromol. Chem. Phys. 2011, 212, 328-335. (1) Vandeleene, S.; Van den Bergh, K.; Verbiest, T.; Koeckelberghs, G. Macromolecules 2008, 41, 5123-5131. 
(m) Grenier, C. R. G.; George, S. J.; Joncheray, T. J.; Meijer, E. W.; Reynolds, J. R. J. Am. Chem. Soc. 2007, 129, 10694-10699. (n) Wen, L.; Duck, B. C.; Dastoor, D. C.; Rasmussen, S. C. Macromolecules 2008, 41, 4576-4578. (o) Heeney, M.; Zhang, W.; Crouch, D. J.; Chabinyc, M. L.; Gordeyev, S.; Hamilton, R.; Higgins, S. J.; McCulloch, I.; Skabara, P. J.; Sparrowe, D.; Tierney, S. Chem. Commun. 2007, 5061-5063. (p) Javier, A. E.; Varshney, S. R.; McCullough, R. D. Macromolecules 2010, 43, 3233-3237.

(5) (a) Yokozawa, T.; Adachi, I.; Miyakoshi, R.; Yokoyama, A. High Perform. Polym. 2007, 19, 684-699. (b) Wu, P.; Ren, G.; Li, C.; Mezzenga, R.; Jenekhe, S. A. Macromolecules 2009, 42, 2317-2320. (c) Ouhib, F.; Khoukh, A.; Ledeuil, J.; Martinez, J.; Desbières, J.; DagronLartigau, C. Macromolecules 2008, 41, 9736-9743. (d) Ohshimizu, K.; Ueda, M. Macromolecules 2008, 41, 5289-5294. (e) Zhang, Y.; Tajima, K.; Hirota, K.; Hashimoto, K. J. Am. Chem. Soc. 2008, 130, 7812-7813. (f) Zhang, Y.; Tajima, K.; Hashimoto, K. Macromolecules 2009, 42, 7008-7015. (g) Van den Bergh, K.; Huybrechts, J.; Verbiest, T.; Koeckelberghs, G. Chem.-Eur. J. 2008, 14, 9122-9125. (h) Van den Bergh, K.; Cosemans, I.; Verbiest, T.; Koeckelberghs, G. Macromolecules 2010, 43, 3794-3800. (i) Smeets, A.; Willot, P.; De Winter, J.; Gerbaux, P.; Verbiest, T.; Koeckelberghs, G. Macromolecules 2011, 44, 6017-6025. (j) Javier, A. E.; Varshney, S. R.; McCullough, R. D. Macromolecules 2010, 43, 3233-3237. (k) Clément, S.; Meyer, F.; De Winter, J.; Coulembier, O.; Vande Velde, C. M. L.; Zeller, M.; Gerbaux, P.; Balandier, J.-Y.; Sergeyev, S.; Lazzaroni, R.; Geerts, Y.; Dubois, P. J. Org. Chem. 2010, 75, 1561-1568. (1) Langeveld-Voss, B. M. W.; Waterval, R. J. M.; Janssen, R. A. J.; Meijer, E. W. Macromolecules 1999, 32, 227-2230.

(6) Ge, J.; He, M.; Qui, F.; Yang, Y. Macromolecules 2010, 43, 6422-6428.

(7) Tkachov, R.; Senkovskyy, V.; Komber, H.; Sommer, J.-U.; Kiriy, A. J. Am. Chem. Soc. 2010, 132, 7803-7810.

(8) (a) Green, M. M.; Reidy, M. P. J. Am. Chem. Soc. 1989, 111, 6452-6554. (b) Green, M. M.; Garetz, B. A.; Munoz, B.; Chang, H. J. Am. Chem. Soc. 1995, 117, 4181-4182.

(9) Senkovskyy, V.; Khanduyeva, N.; Komber, H.; Oertel, U.; Stamm, M.; Kuckling, D.; Kiriy, A. J. Am. Chem. Soc. 2007, 129, 6626.

(10) (a) Miyakoshi, R.; Yokoyama, A.; Yokozawa, T. Macromol. Rapid Commun. 2004, 25, 1663-1666. (b) Lohwasser, R. H.; Thelakkat, M. Macromolecules 2011, 44, 3388-3397.

(11) A zero CD signal is obtained for a rotation of $0^{\circ}$ and $90^{\circ}$ between two polymer chains; a maximum CD signal is obtained for an intermediate angle $\left(\right.$ more or less $45^{\circ}$ ). Smaller and larger angles result in a decrease of the CD signal. Due to the moderate twist $\left(\ll 45^{\circ}\right)$, the actual region is between $0^{\circ}$ and $45^{\circ}$, which implies that an increase of the $\mathrm{CD}$ signal corresponds to an increase of the twist angle.

(12) Smeets, A.; Van den Bergh, K.; De Winter, J.; Gerbaux, P.; Verbiest, T.; Koeckelberghs, G. Macromolecules 2009, 42, 7638-7641.

(13) McCullough, R. D.; Lowe, R. D.; Jayaraman, M.; Anderson, D. L. J. Org. Chem. 1993, 58, 904-912.

(14) Boa, Z.; Lovinger, A. J.; Cherniavskaya, O. Macromol. Symp. 2000, 154, 199-207. 